\title{
Assessment of cardiovascular function following transcatheter aortic valve implantation based on six-minute walk test
}

\author{
Piotr Chodór ${ }^{1}$, Krzysztof Wilczek ${ }^{2}$, Teresa Zielińska ${ }^{1}$, Roman Przybylski ${ }^{3}$, \\ Jan Głowacki ${ }^{4}$, Łukasz Włoch ${ }^{5}$, Marian Zembala ${ }^{3}$, Zbigniew Kalarus ${ }^{1}$ \\ ${ }^{1}$ Department of Cardiology, Congenital Heart Diseases and Electrotherapy, \\ Silesian Center for Heart Diseases, Medical University of Silesia, Zabrze, Poland \\ ${ }^{2} 3^{\text {rd }}$ Department of Cardiology, Silesian Center for Heart Diseases, \\ Medical University of Silesia, Zabrze, Poland \\ ${ }^{3}$ Department of Cardiac Surgery and Transplantology, Silesian Center for Heart Diseases, \\ Medical University of Silesia, Zabrze, Poland \\ ${ }^{4}$ Diagnostic Department, Department of Radiology, Silesian Center for Heart Diseases, \\ Medical University of Silesia, Zabrze, Poland \\ ${ }^{5}$ Students' Scientific Society, Department of Cardiology, Congenital Heart Disease and Electrotherapy, \\ Silesian Medical University, Silesian Center for Heart Disease, Zabrze, Poland
}

\begin{abstract}
Background: Transcatheter aortic valve implantation (TAVI) is presently a recognized treatment modality for patients with severe aortic stenosis ineligible for surgery. It reduces mortality as compared to the conservative treatment. It is further expected from this therapy to improve quality of life by improving of the cardiovascular function performance. The aim of this study is to compare patients'cardiovascular system efficiency in the 6-minute walk test (6MWT) made before and after TAVI and at the 6-12-month follow-up.

Methods: From January 2009 until February 2012, in the Silesian Center for Heart Diseases in Zabrze, TAVI was performed in 104 patients. Eighty-two patients who underwent 6MWT before surgery were qualified for the analysis. The average age of the patients was $76.0 \pm 9.17$ years, women made $45.1 \%$. The risk of surgical treatment according to the Logistic Euroscore averaged $22.76 \pm 12.63 \%$, and by the Society of Thoracic Surgeons - 5.55 $\pm 3.34 \%$. The 6MWT was performed within 1 month before the TAVI procedure, up to a month after the procedure and during the 6-12-month follow-up.

Results: The 6-minute walk test after TAVI was performed by 64 patients, and after 6-12 month follow-up by 46 patients. The average distance in $6 M W T$ increased from $268.4 \pm 89.0 \mathrm{~m}$ before treatment to $290.0 \pm 98.2 \mathrm{~m}$ after the procedure $(p=0.008)$ and $276.1 \pm 93.5 \mathrm{~m}$ to $343.1 \pm 96.7 \mathrm{~m}$ after 6 -12 months $(p<0.0001)$.

Conclusions: Transcatheter aortic valve implantation procedures significantly improve function of the cardiovascular system evaluated by the 6MWT in 1- and 6-12-month observations. (Cardiol J 2017; 24, 2: 167-175)
\end{abstract}

Key words: aortic stenosis, transcatheter aortic valve implantation, 6-minute walk test

Address for correspondence: Piotr Chodór, MD, PhD, Department of Cardiology, Congenital Heart Diseases and Electrotherapy, Silesian Center for Heart Diseases, ul. Curie-Skłodowskiej 9, 41-800 Zabrze, Poland, tel:+48 32 2713414, fax:+48 32 3733792, e-mail: chodor_piotr@go2.pl

Received: 18.05.2016 Accepted: 25.08.2016 


\section{Introduction}

Transcatheter aortic valve implantation (TAVI) is now a recognized therapy for patients with severe aortic stenosis with contraindications to surgery or ineligible for surgery because of the high risks associated with therapy. TAVI procedure reduces mortality in inoperable elderly patients compared with conservative treatment [1]. TAVI can achieve comparable or better results in terms of survival after treatment in elderly patients who require the procedure of surgical aortic valve replacement, but they are at their high risk related with this therapy as compared to surgical treatment $[2,3]$.

In addition, the therapy is also expected to improve the quality of life, i.a. by improving the efficiency of the cardiovascular system. It may be difficult to achieve due to the elderly age of the patients and the presence of comorbidities. The efficiency of the cardiovascular system can be assessed on the basis of efficiency tests, such as an exercise test, spiroergometric test and simply performable 6 -minute walk test (6MWT). This test is optimal to use in elderly patients with aortic stenosis, as it allows to estimate the capacity of the cardiovascular system and to evaluate the symptoms associated with aortic stenosis [4-7]. There are few data in the literature on the 6MWT in patients undergoing TAVI [4-7]. These data are insufficient because they are related to the population of patients at a very old age with many different comorbidities and they are usually short-term observations.

The aim of this study was to evaluate the efficiency of the cardiovascular system in patients before and 30 days after TAVI and at the 6-12-month follow-up based on the 6MWT.

\section{Methods}

From January 2009 to February 2012, in the Silesian Center for Heart Diseases in Zabrze, TAVI was performed in 104 patients. The patients were qualified for the treatment by the multidisciplinary team (Heart Team). Patients with severe symptomatic aortic stenosis, with a surface area of aortic valve in echocardiography (Echo) $<1 \mathrm{~cm}^{2}$, who were inoperable or for whom the risk of surgery by Logistic EuroScore was $>20 \%$ and/or by the Society of Thoracic Surgeons (STS) was $>10 \%$, were qualified for the procedure. Of the 82 selected patients, 46 (56.1\%) had Logistic EuroScore $>20 \%$, and $8(9.8 \%)$ had STS $>10 \%$. Other patients with lower risk (Logistic EuroScore was $<20$ ), but with comorbidities not covered in the scales of risk, however increasing the risk of surgical treatment (e.g. liver failure, porcelain aorta, the state after radiotherapy) were also qualified for TAVI. The lowest Logistic EuroScore was 1.5, the highest risk was $61.5 \%$. The lowest risk assessed by the STS was 0.45 , the highest risk by STS was $14.4 \%$.

Among 36 (43.9\%) patients with Logistic EuroScore < 20\%: $10(12.2 \%)$ patients had coronary artery bypass grafting with the opening of the chest. Twelve (14.6\%) patients had porcelain aorta. Five $(6.1 \%)$ patients had a surgical valve replacement procedure. Nine (11\%) patients had multiple diseases not recognized in the scales of risk. The Heart Team decided to reject the surgery.

Out of 104 patients treated with TAVI, 82 patients underwent $6 \mathrm{MWT}$ before TAVI. The remaining 22 patients did not undergo 6MTW before TAVI for various reasons (patient's refusal, logistic problems, poor mobility, and other) (Table 1).

Only those patients $(n=82)$ who underwent 6MWT before TAVI were enrolled to prospective analysis (Fig. 1).

Of the 82 patients who performed 6MWT before TAVI, 64 patients underwent 6MWT after TAVI in 30-day follow-up and 18 patients did not do 6MTW after TAVI in 30-day follow-up (Fig. 2, Table 2).

Of the 82 patients who performed 6MWT before TAVI and in 30-day follow-up, 46 patients

Table 1. Six patients who did not undergo 6-minute walk test (6MWT) before transcatheter aortic valve implantation for logistic reasons.

\begin{tabular}{lcc}
\hline Patient number & 30-day follow-up 6MWT [m] & 6-12-month follow-up 6MWT [m] \\
\hline 1 & 250 & 231 \\
2 & 272 & Died \\
3 & No data & Died \\
4 & 30 s walk - dyspnea & 189 \\
5 & Valve not implanted - died & - \\
6 & Valve not implanted - died & - \\
\hline
\end{tabular}




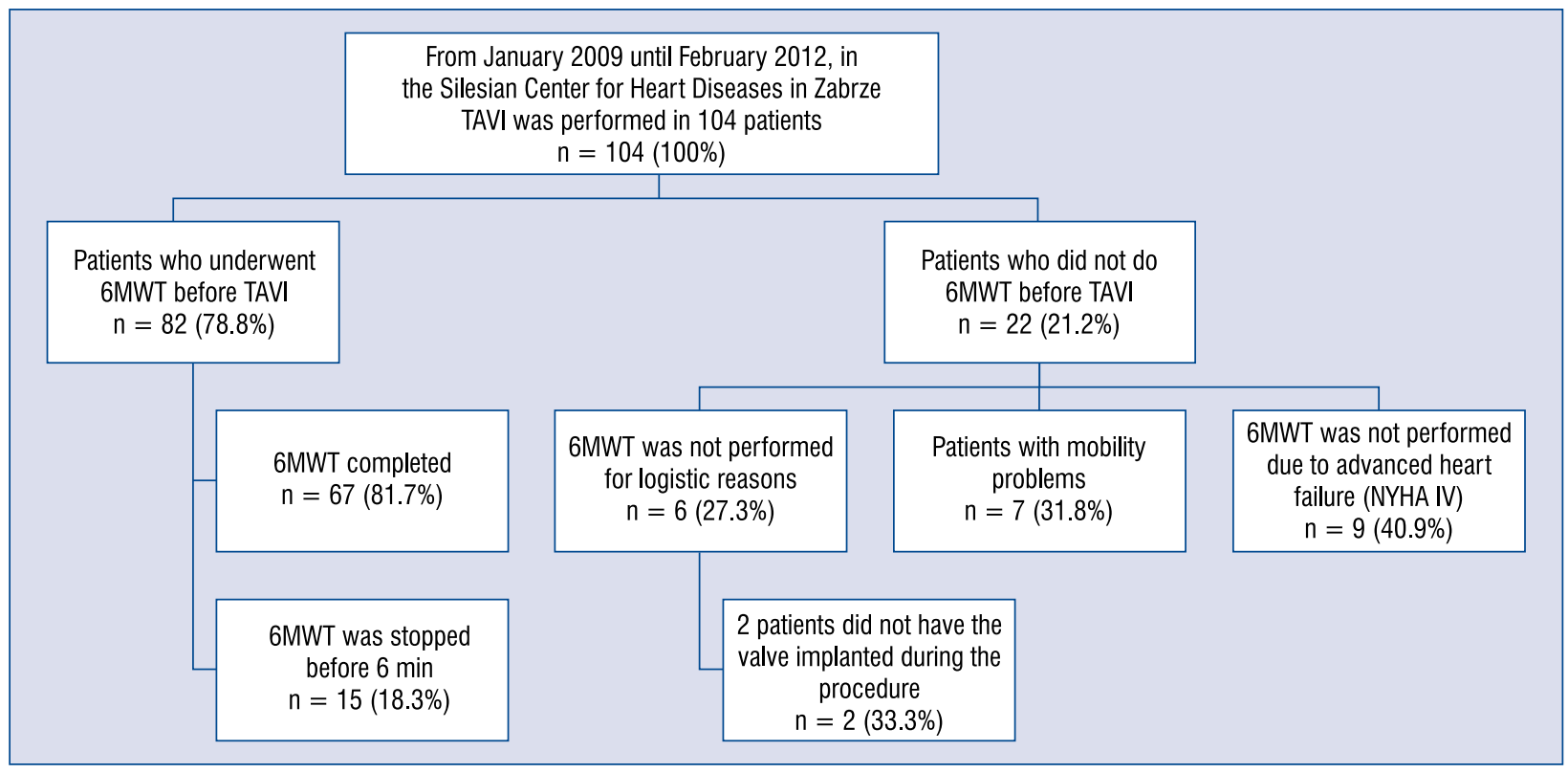

Figure 1. Six-minute walk test (6MWT) before transcatheter aortic valve implantation (TAVI); NYHA — New York Heart Association.

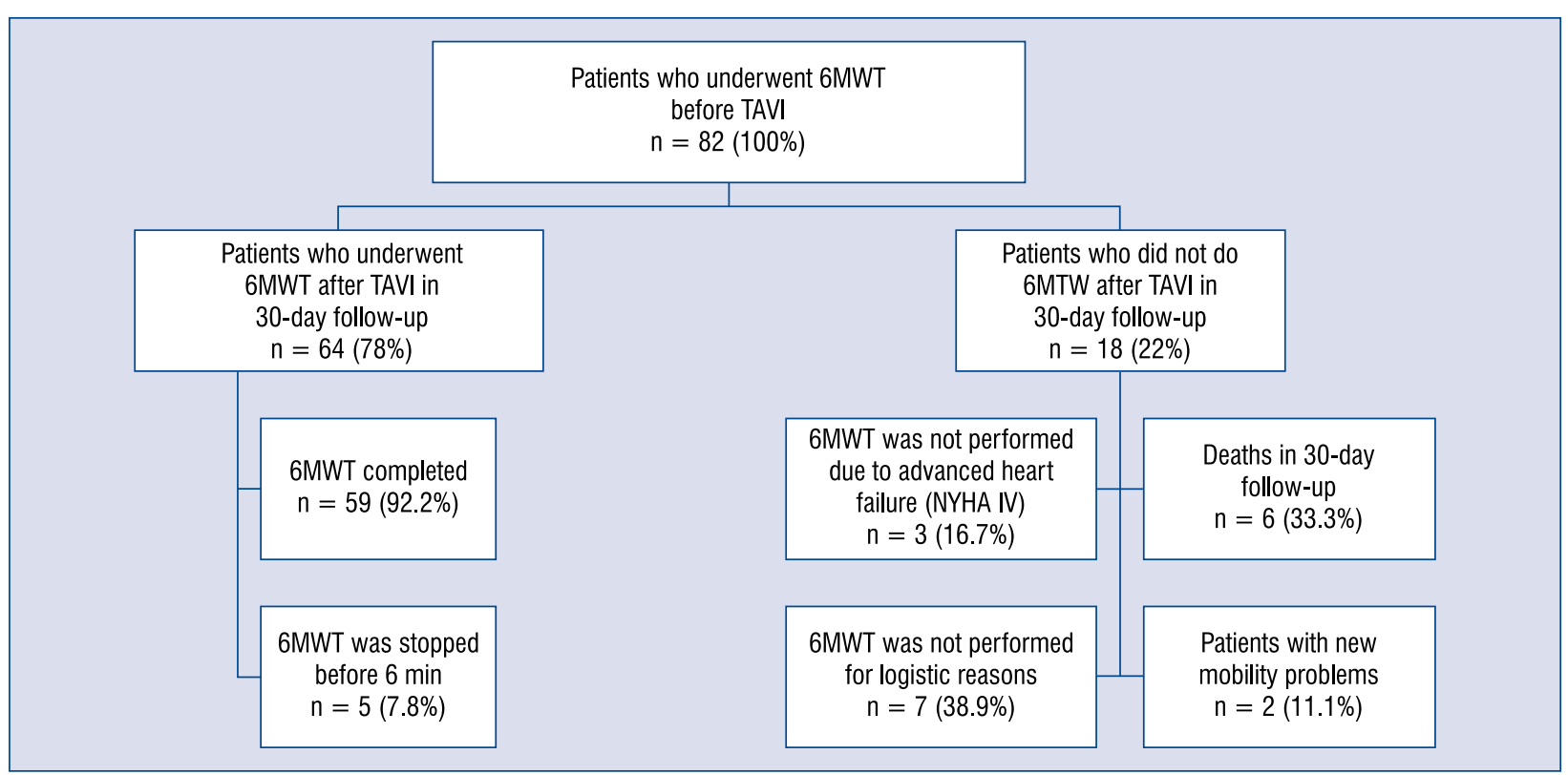

Figure 2. Six-minute walk test (6MWT) in 30-day follow-up; NYHA - New York Heart Association; TAVI - transcatheter aortic valve implantation.

underwent 6MWT after TAVI in 6-12-month follow-up and 36 patients did not do $6 \mathrm{MTW}$ after TAVI in 6-12-month follow-up (Fig. 3).

In 82 patients, $19(23.2 \%)$ Edwards-SAPIEN valves (Edwards Lifescience, Irvine, California) and $63(76.8 \%)$ CoreValve valves (Medtronic, Mineapolis, MN, USA) were implanted.
TAVI procedure was performed via the femoral artery in $50(61.0 \%)$ patients, through the subclavian artery - in $17(20.7 \%)$, through the ascending aorta - in $2(2.4 \%)$, and through the apex of the heart - in $13(15.9 \%)$ patients. The procedures were performed after the evaluation by the multidisciplinary team (Heart Team). The 
Table 2. Seven patients who did not undergo 6-minute walk test (6MWT) in 30-day follow-up for logistic reasons.

\begin{tabular}{lcc}
\hline Patient number & 30-day follow-up 6MWT $[\mathrm{m}]$ & 6-12-month follow-up 6MWT [m] \\
\hline 1 & No data & No data (patient alive) \\
2 & No data & 403 \\
3 & No data & No data (patient alive) \\
4 & No data & No data (patient alive) \\
5 & No data & No data (patient alive) \\
6 & No data & Died (at 3 month) \\
7 & No data & Died (at 2 month) \\
\hline
\end{tabular}

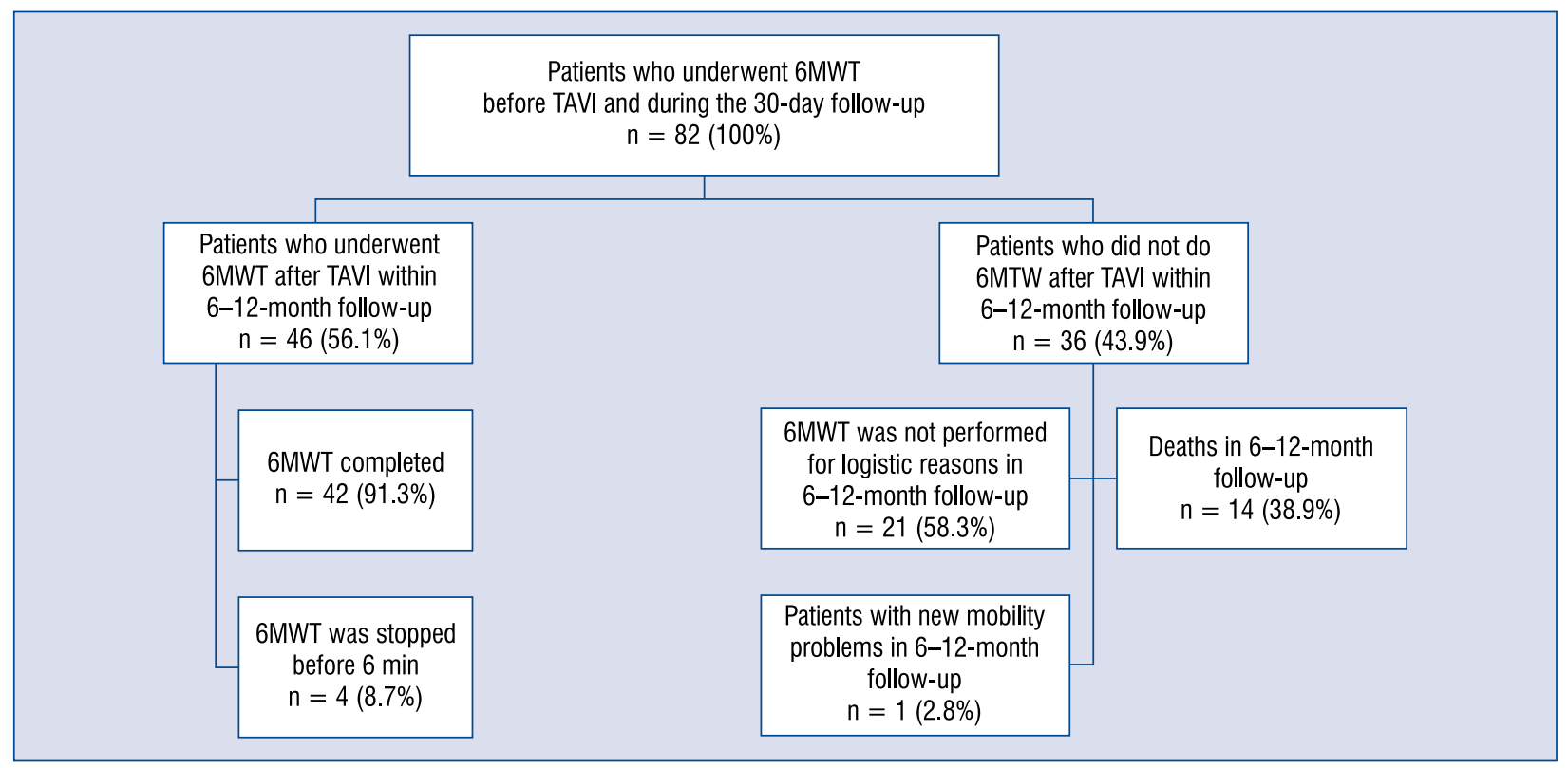

Figure 3. Six-minute walk test (6MWT) in 6-12-month follow-up; TAVI — transcatheter aortic valve implantation.

patients expressed their informed consent to the proposed treatment. The procedures were performed in the catheterization laboratory or in the hybrid operating theatre. Procedures performed transapically, transaortically, through subclavian artery and part of the procedures via the femoral artery were performed under general anesthesia and with the surgical exposing of the access site. Other procedures via the femoral artery were performed in deep sedation, percutaneously, under local anesthesia using vascular closers (Prostar, Proglide).

Before implantation, balloon aortic valvuloplasty was performed while pacing the right ventricle. Edwards-SAPIEN valve sizes of 23,25 and 29, and CoreValve valve sizes of 26, 29, 31 were implanted. The procedures were carried out routinely, as described in previous publications [8-10]. The 6MWT was performed according to the standard procedure in accordance with the guidelines of the American Thoracic Society [11], within a month before TAVI, up to a month after TAVI, and at the 6-12-month follow-up. In patients with New York Heart Association (NYHA) class IV, $6 \mathrm{MWT}$ was not performed. The patients had to bestride a $30-\mathrm{m}$ hospital corridor. The subjects were encouraged to pass the largest distance in $6 \mathrm{~min}$ at their own pace. Before and after the 6MWT blood pressure, heart rate and oxygen saturation were recorded. The distance covered by the patient, the cause of the end of the test, if it was finished ahead of 6 min time, and symptoms occurring during 
exercise were registered. At the end of the test, dyspnea level was determined using a modified Borg scale [12-14]. Before TAVI and during the follow-up appointments, the degree of efficiency of the cardiovascular system according to the NYHA scale was determined.

Before, after TAVI, and during the follow-up appointments, an experienced cardiologist performed the echocardiogram with Philips iE 33 xMATRIX and GE Vivid E9 device.

\section{Statistical analysis}

The received figures were expressed as mean \pm standard deviation. In order to examine the compatibility of distributions with the normal distribution Kolmogorov-Smirnov test was used. If the distributions of the two variables in a pair were consistent with the normal one, T-test was used, and if the result was significant, error bars chart was made (mean and 95\% confidence interval). If at least one of the distributions of variables in a pair differed significantly from the normal one, the Wilcoxon test was used, and if the test showed significant differences, a box chart was made (with marked quartiles and the typical area). To test changes in ordinal variables pairs, Wilcoxon test was used, and to test changes in nominal variables pairs - a sign test was used and frequency tables were made. The level of statistical significance was set at $\mathrm{p}<0.05$. The calculations were performed using IBM SPSS 22.0 software.

\section{Results}

Patient characteristics are shown in Table 3. The results of the 6MWT are given in Table 4 .

In the 6MWT performed 30 days after TAVI, the distance did not increase in $21(32.8 \%)$ patients, while in the $6 \mathrm{MWT}$ made $6-12$ months after the TAVI, the distance did not increase in $12(26.1 \%)$ patients.

Rating of the capacity of the cardiovascular system according to the NYHA scale

Before TAVI, out of 82 patients, 1 (1.2\%) was in NYHA class I, $34(41.5 \%)$ - in class II, and 47 (57.3\%) - in class III. Thirty days after TAVI, 8 $(11.9 \%)$ patients were in NYHA class I, $46(68.7 \%)$ — class II, 10 (14.9\%) - in class III, and 3 (4.5\%) - in NYHA class IV. Before TAVI, cardiovascular fitness according to NYHA averaged $2.54 \pm 0.53$, and 30 days after TAVI $-2.12 \pm 0.66$. There was a significant decrease in the NYHA class range immediately after the procedure $(\mathrm{p}<0.0001)$. In
Table 3. Clinical characteristics of patients.

\begin{tabular}{|c|c|}
\hline $\mathrm{N}$ & 82 \\
\hline Age [years] & $76 \pm 9.17[42-90]$ \\
\hline Women & $37(45.12 \%)$ \\
\hline Height [m] & $1.64 \pm 0.09$ \\
\hline Body mass [kg] & $77 \pm 12.95$ \\
\hline Body mass index $\left[\mathrm{kg} / \mathrm{m}^{2}\right]$ & $28.8 \pm 4.61$ \\
\hline Cigarette smokers & $34(41.46 \%)$ \\
\hline Diabetes & $32(39.02 \%)$ \\
\hline Hypertension & $57(69.51 \%)$ \\
\hline $\begin{array}{l}\text { Creatinine level in blood } \\
\text { serum }[\mu \mathrm{mol} / \mathrm{L}]\end{array}$ & $100.67 \pm 45.52$ \\
\hline GFR $\left[\mathrm{mL} / \mathrm{min} / 1.73 \mathrm{~m}^{2}\right]$ & $70.23 \pm 30.22$ \\
\hline $\begin{array}{l}\text { Patients with renal failure } \\
\left(\text { GFR }<60 \mathrm{~mL} / \mathrm{min} / 1.73 \mathrm{~m}^{2} \text { ) }\right.\end{array}$ & $34(43.04)^{*}$ \\
\hline COPD & $20(24.39 \%)$ \\
\hline A history of past MI & $25(30.49 \%)$ \\
\hline Condition after CABG & $23(28.05 \%)$ \\
\hline $\begin{array}{l}\text { Condition after pacemaker } \\
\text { implantation }\end{array}$ & $17(20.73 \%)$ \\
\hline Patients with $\mathrm{PH}>60 \mathrm{~mm} \mathrm{Hg}$ & $11(23.4 \%)^{* *}$ \\
\hline $\begin{array}{l}\text { SBP in the right ventricle } \\
{[\mathrm{mm} \mathrm{Hg}]}\end{array}$ & $49.46 \pm 16.04$ \\
\hline History of the past BAV & $12(14.63 \%)$ \\
\hline Logistic EuroScore [\%] & $22.76 \pm 12.63$ \\
\hline EuroScore standard & $10.75 \pm 3.56$ \\
\hline STS [\%] & $5.55 \pm 3.34$ \\
\hline LVEF [\%] & $45 \pm 12.21$ \\
\hline \multicolumn{2}{|l|}{$\begin{array}{l}\text { Sufficiency of the cardiovascular } \\
\text { in NYHA: }\end{array}$} \\
\hline Class I & $1(1.2 \%)$ \\
\hline Class II & $34(41.5 \%)$ \\
\hline Class III & $47(57.32)$ \\
\hline
\end{tabular}

${ }^{*} \mathrm{n}=79 ;{ }^{*} \mathrm{n}=47$; CABG - coronary artery bypass graft; COPD chronic obstructive pulmonary disease; BAV - balloon aortic valvuloplasty; GFR - glomerular filtration rate; Logistic EuroScore Logistic European System for Cardiac Operative Risk Evaluation; LVEF - left ventricular ejection fraction; $\mathrm{Ml}$ - myocardial infarction; NYHA - New York Heart Association; PH - pulmonary hypertension; SBP - systolic blood pressure; STS - Society of Thoracic Surgeons score

the $6-12$-month follow-up, $14(30.4 \%)$ patients were in NYHA class I, $29(63.0 \%)$ - class II, and $3(6.5 \%)$ - class III. In the 6-12-month follow-up after the TAVI, cardiovascular fitness according to NYHA averaged $1.76 \pm 0.57$. In the medium-term follow-up, a significant decrease in the NYHA class ( $\mathrm{p}<0.0001)$ was noted.

During 30-day follow-up, 43 (67.2\%) patients had improvement in efficiency of the cardiovascular system. Distance amounted to $309.2 \pm 84.9 \mathrm{~m}$, 
Table 4. Six-minute walk test (6MWT) results.

\begin{tabular}{|c|c|c|c|c|c|c|}
\hline 6MWT & $\begin{array}{c}\text { 6MWT } \\
\text { before TAVI } \\
(n=64)\end{array}$ & $\begin{array}{l}\text { 6MWT 30-day } \\
\text { follow-up } \\
(n=64)\end{array}$ & $\mathbf{P}$ & $\begin{array}{c}\text { 6MWT } \\
\text { before TAVI } \\
(n=46)\end{array}$ & $\begin{array}{l}\text { 6MWT } \\
\text { 6-12-month } \\
\text { follow-up } \\
(n=46)\end{array}$ & $\mathbf{P}$ \\
\hline Distance $[\mathrm{m}]$ & $268.4 \pm 89.0$ & $290.0 \pm 98.2$ & 0.008 & $276.1 \pm 93.5$ & $343.1 \pm 96.7$ & $<0.0001$ \\
\hline $\begin{array}{l}\text { Systolic pressure before } \\
\text { the } 6 \mathrm{MWT}[\mathrm{mm} \mathrm{Hg}]\end{array}$ & $119 \pm 18$ & $123 \pm 17$ & 0.094 & $119 \pm 20$ & $131 \pm 16$ & 0.002 \\
\hline $\begin{array}{l}\text { Diastolic blood pressure } \\
\text { before the } 6 \mathrm{MWT} \text { [mm Hg] }\end{array}$ & $71 \pm 10$ & $71 \pm 9$ & 1.0 & $70 \pm 10$ & $75 \pm 9$ & 0.009 \\
\hline Heart rate before $6 \mathrm{MWT}[/ \mathrm{min}]$ & $73 \pm 13$ & $76 \pm 14$ & 0.044 & $73 \pm 14$ & $74 \pm 12$ & 0.416 \\
\hline $\begin{array}{l}\text { Arterial blood oxygen } \\
\text { saturation before } 6 \mathrm{MWT}[\%]\end{array}$ & $96.1 \pm 1.7$ & $96.4 \pm 1.6$ & 0.353 & $96.0 \pm 1.8$ & $96.3 \pm 1.4$ & 0.168 \\
\hline $\begin{array}{l}\text { Systolic blood pressure after } \\
\text { 6MWT [mm Hg] }\end{array}$ & $135 \pm 22$ & $143 \pm 21$ & 0.006 & $134 \pm 23$ & $147 \pm 18$ & 0.002 \\
\hline $\begin{array}{l}\text { Diastolic blood pressure after } \\
\text { 6MWT [mm Hg] }\end{array}$ & $72 \pm 9$ & $73 \pm 8$ & 0.608 & $71 \pm 9$ & $76 \pm 8$ & 0.016 \\
\hline Heart rate after 6MWT [/min] & $84 \pm 13$ & $91 \pm 14$ & 0.001 & $84 \pm 14$ & $91 \pm 15$ & 0.007 \\
\hline $\begin{array}{l}\text { Arterial blood saturation after } \\
6 \mathrm{MWT}[\%]\end{array}$ & $96.0 \pm 2.7$ & $95.7 \pm 2.5$ & 0.550 & $95.7 \pm 3.0$ & $95.4 \pm 2.2$ & 0.359 \\
\hline $\begin{array}{l}\text { Modified Borg scale after } \\
6 \mathrm{MWT}\end{array}$ & $3.22 \pm 1.4$ & $2.64 \pm 1.0$ & 0.011 & $3.0 \pm 1.5$ & $2.6 \pm 1.5$ & 0.123 \\
\hline Pain in the chest after 6MWT & $13(20.3 \%)$ & $3(4.7 \%)$ & 0.006 & $8(17.4 \%)$ & $1(2.2 \%)$ & 0.016 \\
\hline Dyspnea/fatigue after 6MWT & $50(78.1 \%)$ & $39(60.9 \%)$ & 0.035 & $34(73.9 \%)$ & $33(71.7 \%)$ & 1.000 \\
\hline $\begin{array}{l}\text { Pain in the lower limbs after } \\
\text { 6MWT }\end{array}$ & $44(68.8 \%)$ & $40(62.5 \%)$ & 0.424 & $33(71.7 \%)$ & $27(58.7 \%)$ & 0.070 \\
\hline $\begin{array}{l}\text { Significant increase or } \\
\text { decrease in blood pressure } \\
\text { after } 6 \mathrm{MWT}\end{array}$ & $0(\%)$ & $0(0 \%)$ & 1.000 & $0(0 \%)$ & $0(0 \%)$ & 1.000 \\
\hline Arrhythmias after 6MWT & $0(0 \%)$ & $0(0 \%)$ & 1.000 & $0(0 \%)$ & $0(0 \%)$ & 1.000 \\
\hline
\end{tabular}

$\mathrm{TAVI}$ — transcatheter aortic valve implantation

prior to TAVI was $247 \pm 82.1 \mathrm{~m}(\mathrm{p}=0.001)$. Twenty-one (32.8\%) patients did not achieve better results during the 6MWT. Distance among them was $250.7 \pm 113.3 \mathrm{~m}$, prior to TAVI it was $312.3 \pm$ $\pm 88.4 \mathrm{~m}(\mathrm{p}=\mathrm{NS})$.

During the 6-12-month follow-up, 34 (73.9\%) patients had improvement in efficiency of the cardiovascular system. Distance among them was $360 \pm 102.8 \mathrm{~m}$, before TAVI it was $254.1 \pm 88.7 \mathrm{~m}$ $(\mathrm{p}<0.0001)$. Twelve $(26.1 \%)$ patients did not achieve better results during the 6MWT. Distance among them was $295.4 \pm 56.7 \mathrm{~m}$, prior to TAVI it was $338.2 \pm 80.5 \mathrm{~m}(\mathrm{p}=\mathrm{NS})$.

Of the patients in NYHA class IV before TAVI, $5(55.6 \%)$ patients finished 6MWT during the 30-day follow-up, and 5 (55.6\%) patients finished 6MWT during the 6-12-month follow-up (Fig. 1, Table 5).

Cardiovascular performance and physical fitness after TAVI are displayed in Table 6 .
Rating of the capacity of the cardiovascular system according to the echocardiographic parameters

During 30-day follow-up, in 64 (78\%) patients, echocardiographic parameters of the aortic valve improved. Left ventricular ejection fraction [\%] did not change $(48.2 \pm 10.0$ before TAVI to $47.8 \pm 10.9$ in 30-day follow-up, $\mathrm{p}=\mathrm{NS}$ ). Aortic valve surface area $\left[\mathrm{cm}^{2}\right]$ increased $(0.7 \pm 0.3$ before TAVI to $1.7 \pm 0.6$ in 30 -day follow-up, $p<0.0001)$. Index of the aortic valve surface area $\left[\mathrm{cm}^{2} / \mathrm{m}^{2}\right]$ increased $(0.3 \pm$ \pm 0.1 before TAVI to $0.9 \pm 0.3$ in 30-day follow-up, $\mathrm{p}<0.0001)$. The average gradient through the aortic valve $[\mathrm{mm} \mathrm{Hg}]$ decreased $(53.3 \pm 17.8$ before TAVI to $9.2 \pm 6.1$ in 30-day follow-up, $\mathrm{p}<0.0001$ ).

During the 6-12-month follow-up, in 46 (56.1\%) patients, echocardiographic parameters of the aortic valve improved. Left ventricular ejection fraction [\%] did not change ( $48.3 \pm 9.8$ before TAVI to $49.5 \pm 11.0$ in $6-12$-month follow-up, $\mathrm{p}=\mathrm{NS}$ ). 
Table 5. Patients in NYHA class IV before transcatheter aortic valve implantation.

\begin{tabular}{lcc}
\hline $\begin{array}{l}\text { Patient } \\
\text { number }\end{array}$ & $\begin{array}{c}\text { 30-day } \\
\text { follow-up } \\
\text { 6MWT [m] }\end{array}$ & $\begin{array}{c}\text { 6-12-month } \\
\text { follow-up } \\
\text { 6MWT [m] }\end{array}$ \\
\hline 1 & Still NYHA class IV & Died \\
2 & 460 & 461 \\
3 & 340 & 410 \\
4 & 63 & 90 \\
5 & Died & Died \\
6 & Still NYHA class IV & 189 \\
7 & Died & Died \\
8 & 330 & Died \\
9 & 195 & 265 \\
\hline
\end{tabular}

6MWT - six-minute walk test; NYHA — New York Heart Association

Table 6. Cardiovascular performance and physical fitness after transcatheter aortic valve implantation (TAVI).

\begin{tabular}{|c|c|}
\hline \multicolumn{2}{|l|}{ 30-day follow-up } \\
\hline Longer distance in 6MWT & $43(67.2 \%)$ \\
\hline No improvement & $21(32.8 \%)$ \\
\hline \multicolumn{2}{|l|}{ Including: } \\
\hline $\begin{array}{l}\text { Dyspnea/fatigue (not present before } \\
\text { TAVI) and leg pain (present before TAVI) }\end{array}$ & $3(4.7 \%)$ \\
\hline $\begin{array}{l}\text { Dyspnea/fatigue (present before TAVI) } \\
\text { and leg pain (present before TAVI) }\end{array}$ & $4(6.3 \%)$ \\
\hline $\begin{array}{l}\text { Dyspnea/fatigue (present before TAVI) } \\
\text { and leg pain (not present before TAVI) }\end{array}$ & $2(3.1 \%)$ \\
\hline Leg pain (present before TAVI) & $5(7.8 \%)$ \\
\hline Dyspnea/fatigue (present before TAVI) & $3(4.7 \%)$ \\
\hline No symptoms & $4(6.3 \%)$ \\
\hline \multicolumn{2}{|l|}{ 6-12-month follow-up } \\
\hline Longer distance in 6MWT & $34(73.9 \%)$ \\
\hline No improvement & $12(26.1 \%)$ \\
\hline \multicolumn{2}{|l|}{ Including: } \\
\hline $\begin{array}{l}\text { Dyspnea/fatigue (not present before } \\
\text { TAVI) }\end{array}$ & $2(4.3 \%)$ \\
\hline $\begin{array}{l}\text { Dyspnea/fatigue (not present before } \\
\text { TAVI) and leg pain (not present } \\
\text { before TAVI) }\end{array}$ & $1(2.2 \%)$ \\
\hline $\begin{array}{l}\text { Dyspnea/fatigue (not present before } \\
\text { TAVI) and leg pain (present before TAVI) }\end{array}$ & $2(4.3 \%)$ \\
\hline $\begin{array}{l}\text { Dyspnea/fatigue (present before TAVI) } \\
\text { and leg pain (present before TAVI) }\end{array}$ & $5(10.9 \%)$ \\
\hline Dyspnea/fatigue (present before TAVI) & $1(2.2 \%)$ \\
\hline $\begin{array}{l}\text { Dyspnea/fatigue (present before TAVI) } \\
\text { and leg pain (present before TAVI) and } \\
\text { pain in the chest (present before TAVI) }\end{array}$ & $1(2.2 \%)$ \\
\hline
\end{tabular}

Aortic valve surface area $\left[\mathrm{cm}^{2}\right]$ increased $(0.7 \pm$ \pm 0.3 before TAVI to $1.7 \pm 0.5$ in 6 - 12 -month follow-up, $\mathrm{p}<0.0001)$. Index of the aortic valve surface area $\left[\mathrm{cm}^{2} / \mathrm{m}^{2}\right]$ increased $(0.4 \pm 0.2$ before TAVI to $0.9 \pm 0.3$ in 6 - 12 -month follow-up, $\mathrm{p}<0.0001$ ). The average gradient through the aortic valve $[\mathrm{mm} \mathrm{Hg}]$ decreased $(51.6 \pm 16.6$ before TAVI to $9.0 \pm 4.0$ in $6-12$ month follow-up, $\mathrm{p}<0.0001$ ).

\section{Discussion}

As a result of TAVI, hemodynamic parameters of aortic failure, such as a reduction in average gradient and an increase in aortic valve surface area, were improved. The hemodynamic failure parameters improvement reached immediately after the surgery remained on the same level creating conditions to improve exercise tolerance evaluated in the 6MWT, and to improve the efficiency of the cardiovascular system, evaluated according to the NYHA classification. Many studies evaluating the results of TAVI showed remarkable improvement in the echocardiography parameters of aortic failure and in the capacity of the cardiovascular system, evaluated according to NYHA classification $[1,2,4]$.

The 6MWT is easy to perform, does not require any professional equipment, and can determine the overall exercise capacity of patients [11]. Exercise tolerance depends on the function of many systems, including the cardiovascular system. The 6MWT is used to assess exercise tolerance in patients with various diseases of the respiratory and cardiovascular system. It is also carried out before and after an appropriate method of treatment to evaluate its efficacy in various diseases of respiratory and cardiovascular systems [11]. It can be safely performed in older patients with heart failure and cardiomyopathies [11, 12, 14].

In their study, Gotzmann et al. [4] evaluated 44 patients after implantation of aortic CoreValve by TAVI method. The patients, 30 days after TAVI, covered significantly longer distance when compared to the 6MWT test taken before TAVI (204 \pm $\pm 103 \mathrm{~m}$ vs. $266 \pm 123 \mathrm{~m}, \mathrm{p}<0.001$ ) [4]. Bagur et al. [5] evaluated the usefulness of the 6MWT in 64 patients who underwent TAVI. Six months after TAVI they achieved a significant increase in the distance covered during the test $(165.3 \pm 79.7 \mathrm{~m}$ before TAVI to $231.7 \pm 88.9 \mathrm{~m} 6$ months after TAVI, $\mathrm{p}<0.0001$ ).

The authors of this study noted that there are about $25 \%$ patients out of the study group, in whom there was no growth or even a decline in the dis- 
tance achieved in the 6MWT. Kleczyński et al. [7] evaluated 40 patients after the TAVI. After 12 months, they reported the largest increase in the walking distance in the 6MWT. It went up from $200 \mathrm{~m}$ before treatment to $325 \mathrm{~m} 12$ months after TAVI. In the present study, 82 patients who underwent 6 MWT prior to surgery and 6-12 months after surgery were evaluated. Not only the length of distance, but also various parameters of the effort test were rated, finding out that most of them improved after TAVI procedure. In this study, the distance in long-term follow-up increased from $276.1 \pm 93.5 \mathrm{~m}$ before the surgery to $343.1 \pm 96.7 \mathrm{~m}$ after the surgery $(\mathrm{p}<0.0001)$.

Initially, it was the longest distance observed in patients before TAVI and these patients achieved the longest distance after the surgery in the 6-12-month follow-up. These differences may be due to the characteristics of the group of people eligible for TAVI, age, comorbidities, as well as the fact that the $6 \mathrm{MWT}$ was not carried out among the most seriously ill (NYHA IV e.g.).

The PARTNER study showed comparable survival in patients after TAVI and patients after cardiac surgical treatment, and the study of Adams et al. [3] showed improvement in survival in the group treated by TAVI [2]. In addition to the observed improved survival, some studies also reported the improvement in life quality compared with the cardiac surgical therapy [7]. Life quality improvement can be also assessed indirectly through the 6MWT, which is an objective test reflecting everyday life activity. In the present study, no improvement in the 6MWT was observed in $32.8 \%$ of patients after 30 days, and after $6-12$ months, still no improvement was noted in $23 \%$ of patients. Similar observations were made by Bagur et al. [5] who found out that as many as $1 / 4$ of patients in the 6MWT did not improve or even deteriorated. It can be assumed that elderly patients and patients with comorbidities do not fully benefit immediately after the surgery. However, in the further period, still a large group of patients do not show any improvement in the 6MWT.

Moreover, there is a certain disproportion between the improvement in terms of the capacity of the cardiovascular system according to NYHA classification (approximate scale and difficult to assess in the elderly) and the fact that many patients reached no improvement in the 6MWT. This may result from qualifying for TAVI patients with severe stenosis of the aortic valve, and from the deterioration in exercise tolerance as the main symptom. It is very difficult to determine in elderly patients, whether this symptom is closely associated with aortic stenosis. This may depend on other comorbidities, therefore no improvement is observed in some patients after properly conducted TAVI procedure.

The fact that a certain group of patients do not improve their condition may depend, as previously noted, on the comorbidities, such as the severity of coronary artery disease, incomplete revascularization before TAVI, cardiomyopathies, mitral insufficiency, pulmonary hypertension, chronic obstructive pulmonary disease or common, at the older age, anemia and orthopedic problems.

\section{Limitations of the study}

The study was conducted in one center and included a small number of patients. Many patients could not arrive to participate in the study for logistic reasons.

\section{Conclusions}

1. After TAVI, a significant improvement in the 6MWT distance was achieved in the 30-day follow-up and even greater improvements in the later period (6-12 months).

2. An improvement was reported in various parameters of the 6MWT in the 30-day follow-up - a higher pulse rate before and after the test, higher systolic blood pressure after the test, smaller value in the Borg scale and lower incidence of chest pain and breathlessness and dyspnea/fatigue after the test.

3. The 6-12-month follow-up showed significant improvements in individual parameters of the $6 \mathrm{MWT}$ - higher pulse rate after the test, higher systolic and diastolic blood pressure before and after the test, and a lower incidence of chest pain. There was no improvement in the assessment of dyspnea according to the modified Borg scale and a significant reduction in dyspnea/fatigue after the 6MWT.

4. There was a significant improvement in efficiency of the cardiovascular system evaluated according to NYHA classification after the TAVI in the 30-day and the 6-12-month follow-ups.

5. After TAVI, a significant improvement in echocardiographic parameters of aortic valve failure was recorded. During 30-day followup and the 6-12-month follow-up increased: aortic valve surface area, index of the aortic valve surface area, and decreases the average gradient through the aortic valve.

Conflict of interest: None declared 


\section{References}

1. Leon MB, Smith CR, Mack M, et al. PARTNER Trial Investigators. Transcatheter aortic-valve implantation for aortic stenosis in patients who cannot undergo surgery. N Engl J Med. 2010; 363(17): 1597-1607, doi: 10.1056/NEJMoa1008232, indexed in Pubmed: 20961243.

2. Smith CR, Leon MB, Mack MJ, et al. PARTNER Trial Investigators. Transcatheter versus surgical aortic-valve replacement in high-risk patients. N Engl J Med. 2011; 364(23): 2187-2198, doi: 10.1056/NEJMoa1103510, indexed in Pubmed: 21639811.

3. Adams DH, Popma JJ, Reardon MJ, et al. U.S. CoreValve Clinical Investigators. Transcatheter aortic-valve replacement with a selfexpanding prosthesis. N Engl J Med. 2014; 370(19): 1790-1798, doi: 10.1056/NEJMoa1400590, indexed in Pubmed: 24678937.

4. Gotzmann M, Hehen T, Germing A, et al. Short-term effects of transcatheter aortic valve implantation on neurohormonal activation, quality of life and 6-minute walk test in severe and symptomatic aortic stenosis. Heart. 2010; 96(14): 1102-1106, doi: 10.1136/hrt.2009.180661, indexed in Pubmed: 19884109.

5. Bagur R, Rodés-Cabau J, Dumont E, et al. Exercise capacity in patients with severe symptomatic aortic stenosis before and six months after transcatheter aortic valve implantation. Am J Cardiol. 2011; 108(2): 258-264, doi: 10.1016/j.amjcard.2011.03.031, indexed in Pubmed: 21545988.

6. Green P, Cohen DJ, Généreux P, et al. Relation between sixminute walk test performance and outcomes after transcatheter aortic valve implantation (from the PARTNER trial). Am J Cardiol. 2013; 112(5): 700-706, doi: 10.1016/j.amjcard.2013.04.046, indexed in Pubmed: 23725996.

7. Kleczyński P, Bagieński M, Sorysz D, et al. Short- and intermediate-term improvement of patient quality of life after transcathe- ter aortic valve implantation: a single-centre study. Kardiol Pol. 2014; 72(7): 612-616, doi: 10.5603/KP.a2014.0065, indexed in Pubmed: 24671914.

8. Chodór P, Wilczek K, Przybylski R, et al. Immediate and 6-month outcomes of transapical and transfemoral Edwards-Sapien prosthesis implantation in patients with aortic stenosis. Kardiol Pol. 2010; 68(10): 1124-1131, indexed in Pubmed: 20967708.

9. Wilczek K, Chodór P, Walas R, et al. "Vale-in-valve" - first Polish experience in transcatheter treatment of patient with high-risk of redo surgery for degenerative disease of aortic bioprosthesis, using tranaxillary access. Kardiol Pol. 2010; 68(8): 980-984, indexed in Pubmed: 20730744.

10. Wilczek K, Chodór P, Laborde JC, et al. [Percutaneous transfemoral aortic CoreValve(R) implantations in high risk patients-another Polish good experience]. Kardiol Pol. 2009; 67(10): 1162-1165, indexed in Pubmed: 20017087.

11. ATS Committee on Proficiency Standards for Clinical Pulmonary Function Laboratories. ATS statement: guidelines for the six-minute walk test. Am J Respir Crit Care Med. 2002; 166(1): 111-117, doi: 10.1164/ajrccm.166.1.at1102, indexed in Pubmed: 12091180.

12. Bruce RA. Exercise testing of patients with coronary heart disease. Principles and normal standards for evaluation. Ann Clin Res. 1971; 3(6): 323-332, indexed in Pubmed: 5156892.

13. Crawford M, O'Rourke RA, Ramakrishna N, et al. Comparative effectiveness of exercise testing and continuous monitoring for detecting arrhythmias in patients with previous myocardial infarction. Circulation. 1974; 50(2): 301-305, indexed in Pubmed: 4846637.

14. Shaw DJ, Crawford MH, Karliner JS, et al. Arm-crank ergometry: a new method for the evaluation of coronary artery disease. Am J Cardiol. 1974; 33(6): 801-805, indexed in Pubmed: 4824854. 